\title{
The Analysis of Classification and Selection Strategies in PE Teaching Mode
}

\author{
Liang Luo ${ }^{1}$ \\ ${ }^{1}$ Dengyun Vocational College of Science and Technology, Kunshan, Jiangsu, 215300 \\ Fund project: Distinguished Course "Physic and Health" in Dengyun Vocational College of Science and \\ Technology. \\ hunter2011@foxmail.com
}

Keywords: PE Teaching Mode, Classification, Selection, Strategies, Countermeasures

\begin{abstract}
The economic development not only improves the living standards, but also brings competitive pressure to more and more people, sub-health has become an important factor affecting people's quality of life. The sub-health problem is also increasingly evident in our young students. Therefore, making efforts to improve physical education teaching quality and improving sports teaching model has become the research focus of the majority of educators in recent years. This article will focus on the classification and selection strategies of physical education teaching mode and put forward the guiding policy in order to help improve the sports teaching quality.
\end{abstract}

\section{Introduction}

With the deepening of education reform in recent years, sports, academic thinking and practice related to Physical Education Teaching Mode of very active, and has presented a diversity of sports teaching mode, abandoned the previous old teaching model. Physical Education Teaching Mode of Physical Education is to connect thought and practice of combining academic bridge, the whole process and the Department of Physical Education Physical education system specific, practical technology, to some extent, under the guidance of teaching ideas, in particular the teaching environment, the advance objectives and provisions of good teaching to complete the task of teaching, teaching procedures posed with special properties, including teaching methodologies and adapt very stable structure of the teaching process [1].

Discussion on Physical Education Teaching Model for promoting physical education, the effective implementation of quality education, physical education combining academic thought and practice of strengthening and promoting sports teaching reform and development, improve the quality of teaching, and promote continuous improvement of sports teaching mode is of great significance. Discussion on sports in the past in the teaching mode, although we have some results, but some aspects are still not able to reach a consensus, such as sports teaching mode characteristics, classification problems, especially in terms of choice to explore is very weak, so some sports teaching model in practice applied directly affected. The correct selections of the good sport teaching mode, and an in-depth inquiry, and constantly improve PE teaching theory is that we must solve the problem before we face. Therefore, the systematic exploration of Physical Education Model was necessary.

\section{The Core Features of Physical Education Teaching Mode}

Construct closed cooperation learning relationship among students. Students under the correct guidance of sports trainers to the group as a unit, combined unit with course objectives and team characteristics, team selection and related content, using the knowledge of the new sports knowledge and sports action methods to implement systems to explore, and finally into the induction, after summary Panel of collective conclusion. In this learning phase between high school students become independent from the original subject of close cooperation partnership, embodied in three 
aspects of this support depend, namely: (1) target interdependent. Each team unit members need to work together to complete to achieve their learning goals set in advance, for each individual member of the movement by the common task of the contents of the unified group, as long as each member have reached their assumed motion effects, Group units goal can be achieved. (2) role interdependencies. Explore each other within the group required constitute a clear division of labor complement and support the role of the group system. (3) mutually dependent of resources. To achieve common learning goals, we must exchange information among team members of the unit and share relevant information. In such influence mutually dependent relationship between the students from the original competition into cooperation by individual behavior change as a collective wisdom, which highlights the interaction, solidarity and a new pattern of collaboration [2].

Student is the host of the learning activity. Sports and wellness focus is to meet student needs and concerns of students experience emotional feelings, in order to promote the comprehensive development of the growth of talent, from the curriculum frameworks to program evaluation and many other areas, has been the active learning at the center of the entire work, students to explore cooperation in the target can be pointed out that the freedom to summarize ideas and thinking question, constantly conscious of their individual thought potential role in other aspects of knowledge and ability to make up a short board, completely changed in the past students just passive acceptance of old teaching mode, so that the students themselves as masters of learning activities.

Control the target. Each stage has a strong teaching purpose, teaching each stage can feel the goal to explore the behavior of the regulation. Implementation constraints and control for the problem with off-track student behavior that may occur during the learning phase, the full play the main role of teachers. The construction of the target is based on the national curriculum goals and curriculum objectives do guidance, and by the cell targets, objectives and goals of the group courses set up their own constitution.

\section{The Classification of Sports Teaching Mode}

Traditional sports teaching mode. Traditional teaching model the majority of parents and school are focused disciplines, rather than on the development of sports and physical fitness of students a high degree of concern. Physical aging school teaching equipment is not complete so physical education in schools has become a kind of decoration. Many schools have even secretly changed in physical education self-study courses, students studying together in the classroom. Students also relatively insensitive to physical education that school is important, physical education does not matter. The traditional teaching model is also relatively rigid and teachers must first explain the teaching requirements, a simple warm-up exercise on freedom disbanded. No substantial physical exercise and should be regarded as teaching model type of skill to master [3].

Focus on developing teaching mode. In modern times, sport has become a relatively mature field of education and its content has been extended to aspects of health education, psychological development, behavior and safety education. Physical education requirements and students 'age correspond to the current high school physical education should be based on the particularity of their age targeted use of certain teaching model, we found that PE teaching model law is a way to cultivate students' positive self-activity, so its ability to improve independent inquiry learning to master sports teaching methods, understanding and problem-solving at the same time, we should pay attention to research and apply. Allow students to learn the joy of faith, the joy of fitness. Teachers program is designed to exercise a dominant ideology, some of the best sports games designed to improve the classroom atmosphere relaxed. We can organize some games, such as skipping loser and design competitions, relay race, hurdle race, tug of war, and so on to make a number of measures to stimulate the enthusiasm of the students.

Incentive teaching. The development focus is different according to different focus for different schools. Such as Tohoku Electric Power University Dragon Boat very enjoy reputation in 
the domestic, but also have a special boat respective venues and more authoritative dragon boat coach. Every year, out of the province to participate in major competitions and achieved reputation. This form of motivation of the students desire to study sports competing interests and apply learning, and for having a body in the ranks among the outstanding teaching ability, will always have a collective sense of honor. Schools can be based on objective teaching environment for students of their schools were focused culture, which is certainly a good teaching model

Elective Teaching. Now many universities have adopted the elective teaching mode, to give full play to the leading role of the main role of teachers and students, promote an open, inquiry-based teaching, under the guidance of teachers, students should have to choose course content, choose classroom teachers, the freedom to choose class time. Group for students interested in sports subjects for their selection, teachers choose their own interest, thus avoiding the kind of past persecution students in class, the students do not love school phenomenon, the students themselves to learn the subjects, students the interest must be very high. Learning atmosphere will be very good and such teaching had a very positive impact.

Yoga Teaching. Yoga is an excellent movement of self-cultivation method and the school should apply for some high-end yoga teacher for teaching yoga to students in the major fitness areas will have a yoga instructor. In teaching yoga now not very widely gained popularity, so the major schools should consider the introduction of teaching yoga. A complete yoga teaching model should include the following six elements: guiding ideology, theoretical foundation, sports objectives, operating procedures and methods, applicable conditions and course evaluation.

\section{The Selection Policy of Physical Education Teaching Mode}

Combined with the purpose of the physical education teaching. Physical Education Teaching Model goal is not only the starting point for sports, but also the focus of Physical Education Teaching Mode. Because to a certain extent, bound to live sports and teaching activities of teaching goal, we should combine different teaching objectives, and take it with appropriate, consistent with the teaching model [4].

Combined with the development level of the students. Students of different ages reflect physiological development situation, characterized by the ability to acquire knowledge is not the same, the students of the same age, which reflect the level also vary. So the choice of sports teaching model must focus on ability and level of cognitive development of students, teaching mode should be the same level of development of the majority of students to conform to the benchmark.

Combined with teaching environment and teaching conditions. We are talking about here involves more extensive teaching environment, teaching conditions, including the site of the equipment, the number of students, teaching hours, teachers of physical ability and other factors. These factors should be combined with a reasonable choice of teaching in the teaching mode. For example: many people faced with classes, teaching time is short, conditions are relatively poor teaching facilities, teachers' experience is limited capacity in some cases, you can select the system learning mode; fewer people face a number of classes, teaching time relaxed, teacher experience and strong capability, etc., can be Select the mastery learning teaching. In addition, it should be combined with changes in the characteristics of the diversification process of teaching and teaching goals, comprehensive selection, use the Implementation of Physical Teaching. Complain sports teaching mode in real teaching, too monotonous cry constantly, but from the classified PE teaching mode, we will find the kind of PE teaching model is not currently very little. Why Departments of Physical Education in the objective pattern than a single issue will happen. We think there are three factors, namely: poor (1) Applicability objectively existing sports teaching mode; (2) teachers understand the contents of the existing mode only surface, no deep understanding of other contents; (3) selection When the teaching mode, consciously, unconsciously exclude the other modes, only highlights a particular model [5]. 
As it can be seen from the above reasons, the objective practical difference after sports teaching model to eliminate this factor, resulting in drab objective reasons together sports teaching mode that is not implemented a comprehensive selection and use of physical education teaching. In fact, sports teachers in the teaching mode selected must be clearly recognized: does not exist can be effectively tailored to each student successfully achieved or whether any PE teaching mode for all teaching objectives, that certain sports teaching mode has its unique functionality and usability. Admittedly, we do not deny a teaching goal to have more than one teaching mode to adapt thereto, does not rule out any teaching model can achieve a lot of teaching goal, but despite "a mold universal" teaching model, the public mind is desirable, however, You can not become a reality. Teaching model is specific; teaching model is targeted; teaching mode is limited. So in reality PE teaching should be combined with the actual situation of teaching objectives Smart comprehensive selection of sports teaching mode.

\section{Conclusion}

The physical education model is a teaching program which reflects the physical education ideology and it is the link connects sports teaching ideas with PE teaching practice. With the deepening of the new curriculum reform, improving teaching effectiveness and building effective class have become our common goal. How to use the sports teaching mode rationally in sports teaching practice activities is the key to solve the detachment of current sports theory with practice.

\section{References}

[1] X.Zhang, The selection policy of physical education model under the concept of new course, Education, 5(2007) 46-47.

[2] C. Li, Contemporary physical education guide the transformation of sports teaching model, China Education Innovation Herald, 11(2006) 26-30.

[3] C.Y.Wang, PE teaching mod, Journal of Zhengzhou Railway Vocational and Technical College, 12(2009) 56-58.

[4] J.X.Li, Teaching strategies and the implementation requirements of the physical education model, Science \& Education, .9(2009) 19-22.

[5] Y.X.Zhang, Strategies for Teaching Model, Theory of Urban Construction, 4(2007) 129-132. 